\title{
Prescribing and the regulation of formulation
}

\author{
A. H. BECKETT \\ Ph.D., D.Sc., F.P.S. \\ Chelsea College, University of London
}

\begin{abstract}
Summary
Unless the equivalence of different products has been established, the prescriber must define the product he requires by using the trade name. Present pharmacopoeial standards based on in vitro methods are inadequate to predict equivalence in man. There are many ways in which differences in formulation may influence absorption of drugs, and only comparable absorption profiles can be taken as evidence of equivalence.
\end{abstract}

SUFFICIENT evidence has already been provided in the preceding papers to support the view that 'different formulations of the same drug may vary in their bio-availability to a clinically relevant extent, and there may be variations between batches as a result, for example, of minor changes in manufacturing procedures. Drugs from different sources should therefore be considered as distinct products or formulations whose equivalence cannot be assumed on the basis of present pharmacopoeial standards'.

We have also heard sufficient evidence for me to make the statement, which is in line with thinking in many countries: compliance with official standards does not guarantee the efficacy of a product.

The heart of the problem is that we do not make a drug to give to man. The drug is first converted to a medicine by the process of formulation (Fig. 1). We take the drug, the active principle, the quality of which can be guaranteed by compliance with official standards. But we do something with it before the patient gets it, which includes the use of additives, i.e. disintegrants, lubricants, and the standardization of these materials is also important but frequently not carried out. For medicines, i.e. the formulated product, or the drug delivery system, compliance with official standards alone does not guarantee quality.

Now I want to give a few examples of the problems we have to face. The first illustrates the importance of drug absorption profiles - it is the profile and not the total amount of drug absorbed which determines the bio-availability. Figure 2 illustrates a drug in three different products A, B and C. The amount of drug absorbed from products $A$ and $B$ is equal but the profiles are different and the clinical effects obtained from these two products are also different. With product $\mathbf{C}$ absorption is poor and the profile is also different. So with different formulations, we can get into a whole variety of problems.

Table 1 lists the ways in which differences in the formulation of a drug can lead to problems of bioavailability. We can define particle size and physical form in a drug, but what about in the product? Sometimes salts of a drug have been regarded as equivalent to the parent base by official bodies. Unsuitable substances have been used for filling capsules. Is the content of capsules designated in official standards? It is well known that some enteric-coated and sugar-coated tablets may pass through the gastrointestinal tract unchanged, and yet they comply with official standards. Are we not aware that depending on the drug inside the enteric-coated product we can have compliance with official standards, but some products release drug in the stomach, some release lower down and some pass through unchanged?

\begin{tabular}{lll|}
\hline DRUG & FORMULATION & MEDICINE \\
(Active principle) & $\begin{array}{l}\text { (Addition of other } \\
\text { materials and } \\
\text { compounding) }\end{array}$ & $\begin{array}{l}\text { (Pharmaceutical } \\
\text { preparation or } \\
\text { product) }\end{array}$ \\
$\begin{array}{l}\text { Quality: compliance } \\
\text { with official standard } \\
\text { guarantees quality }\end{array}$ & $\begin{array}{l}\text { Standardization of } \\
\text { materials, methods } \\
\text { and manufacturer } \\
\text { is important }\end{array}$ & $\begin{array}{l}\text { Quality: compliance } \\
\text { with official standards } \\
\text { alone DOES NOT } \\
\text { guarantee quality }\end{array}$
\end{tabular}

FIG. 1. Stages in the conversion of a drug into a medicine by formulation. 


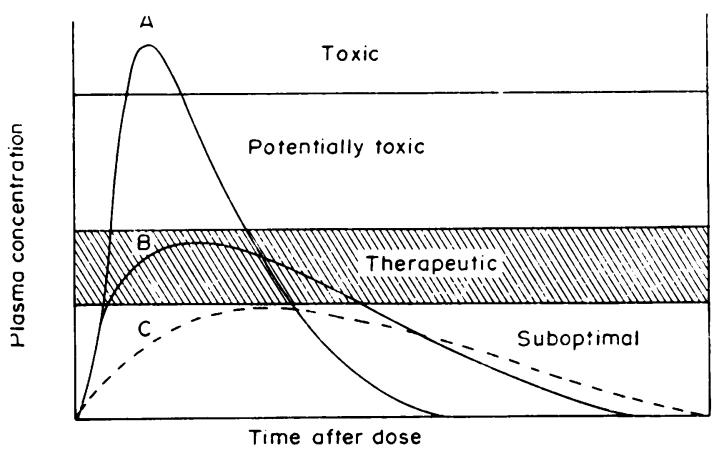

Fig. 2. Influence of rate of drug delivery from a medicine on therapeutic activity.

TABle 1. Causes of lack of quality in medicines leading to problems of drug availability

Unsuitable drug particle size
Unsuitable drug physical form
Unsuitable salt or drug
Unsuitable capsule contents for capsule form
Unsuitable adjuvants for drug in capsule or tablet
Unsuitable product coatings
Unsuitable enteric coatings
Unsuitable base for drug in ointment or suppository
Powder compaction in tablets
Microbial contamination in non-sterile product
Non-sterility in sterile product.

There are many important examples of differences in bio-availability associated with different formulations. Absorption of phenacetin is greatly affected by differences in particle size. Figure 3 illustrates the blood levels obtained by equivalent doses of an antibiotic in three forms; the absorption of the drug from a capsule without additives is very poor. Thus it is no good thinking that one can take a known drug, put it into a capsule as some people do in clinical trials, and assume that the drug is completely available for absorption. Some people will argue that it does not matter when repeated doses are used, but in many cases differences in bio-availability give differences in steady state levels of drug.

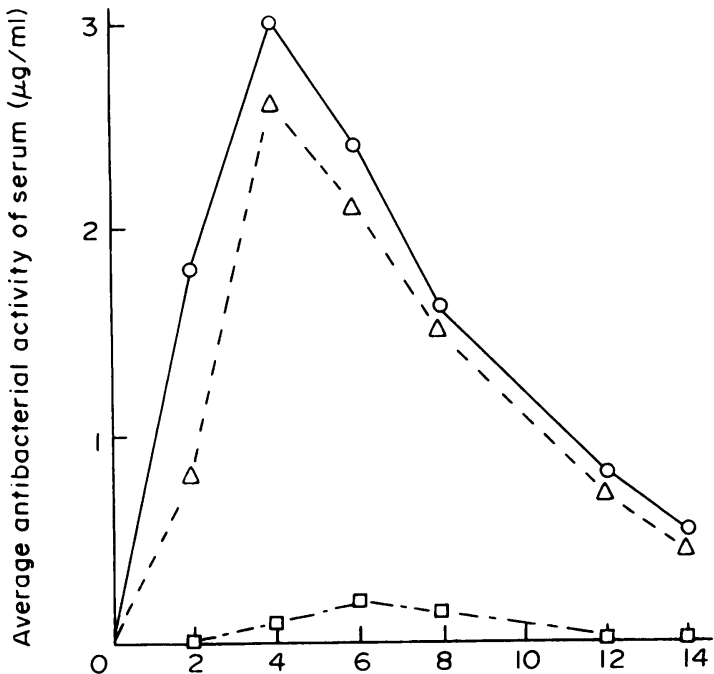

Time after single dose (hr)

Fig. 3. Equivalent single doses of an antibiotic administered orally in three forms. $\mathrm{O} O$, aqueous suspension of antibiotic derivative; $\triangle---\triangle$, aqueous solution of parent antibiotic; $\square-.-\square$, antibiotic derivative as powder in capsule without additives.

Salicylamide illustrates the importance of dosedependent kinetics. When the dose of salicylamide or bio-availability is increased in some people, the blood level of the drug does not change much until a certain point is reached and then it rises very steeply. On this part of the curve, increasing the dose or bio-availability by $25 \%$ can raise blood levels by $1000 \%$. Can this be called unimportant?

We have considered briefly the efficacy of medicines but we must also consider safety. Table 2 gives three examples of drug toxicity produced by changes of formulation. In Australia and New Zealand, diphenylhydantoin capsules were formulated using an insoluble diluent and epileptic patients were controlled with this type of capsule. The manufacturers,

TABLE 2. Examples of lack of safety of drugs, produced by changes in drug formulation

\begin{tabular}{ll}
\hline \multicolumn{1}{c}{ Drug } & $\begin{array}{l}\text { Toxic symptoms upon change of formulation with dose } \\
\text { unchanged }\end{array}$ \\
\hline Enteric coated aspirin & $\begin{array}{l}\text { Product A: little success in treating rheumatoid arthritis } \\
\text { Product B: toxic, reduction of dose required }\end{array}$ \\
Diphenylhydantoin capsules & $\begin{array}{l}\text { Capsule-calcium sulphate diluent: patients adequately } \\
\text { controlled } \\
\text { Capsule-lactose diluent: epidemic of toxic symptoms in } \\
\text { Australia }\end{array}$ \\
$\begin{array}{l}\text { Chlorthiazide-potassium } \\
\text { chloride tablets }\end{array}$ & $\begin{array}{c}\text { Some formulations but not others caused numerous } \\
\text { intestinal perforations, some of them fatal }\end{array}$ \\
\hline
\end{tabular}


with the permission of the regulatory body, changed the diluent to lactose which is soluble. This allowed the drug to be rapidly absorbed and there was an epidemic of toxic reactions. Some people argue that if this sort of problem occurs, it will be noticed by doctors. Why didn't they see it earlier in Australia? How many people suffered from intestinal perforations due to potassium chloride before anyone noticed? I do not accept that even substantial changes in the effects of different products will be observed and reported. And I question the value of adverse drug reactions reported on generic products. If the products vary so much in terms of toxicity, such information without defining the product is meaningless because it compares like with unlike. All products are not identical and we cannot assume that generic brands are equivalent to each other or to the branded product.

Clinical trials deserve emphasis. When we use a standard in clinical trials which is not the brand name product, whose properties are usually well defined, then we have to ensure that the standard has an equivalent biological profile in man to that of the brand name product; it is profile and not bioavailability that matters. People say this is obvious. If it is obvious, why do medical journals publish their standards in clinical trials under generic names? Why in London relatively recently in three trials were brand name tablets crushed up, extracted, reformulated and the new products used as standards? Can we attach significance to clinical trials where the standard is an unspecified product? Many people put the tablet into a capsule to make different products look the same but the absorption profile must be checked before this can be accepted as not interfering with the release of drugs from the tablet. One company used evidence of bio-availability in applying for a compulsory licence. They made a tablet to compare with the brand name tablet and set out to prove that there was an equivalent bioavailability. When these two tablets were compared, they were both crushed up, made into suspensions, used on the wrong animal species in inadequate doses with little response from either. This was presented as evidence of similar bio-availability of brand and generic product; the compulsory licence was granted.

We are approaching an era of much more sophisticated formulations. Instead of pilocarpine eye drops there will be preparations which will release the drug for many days. Can these be regarded as the same as pilocarpine eye drops and prescribed under the same name? There is now an interuterine device available which releases progesterone over a year and the amount of progesterone released is only equivalent to that in two tablets of progesterone. We cannot talk of generic equivalents in the case of sophisticated formulations. I stress that a drug and a medicine must not be regarded as the same thing.

Speaking now in the interests of the patient, we surely need a product which can be guaranteed for the medical practitioner even though it may have a different name. Doctors working in hospitals do not usually know the name of the manufacturer whose product is dispensed under the generic name. These doctors in the hospital do not know what their patients are really getting. And then when the patient goes out of hospital, the pharmacist who continues to supply his treatment does not know what has been given. What is he supposed to do? Give another brand product or another generic. Surely something must be done to clarify the situation.

Returning to standardization, we must define the problems which are likely to arise with certain drugs and certain formulations. I accept that there may be some cases where formulation is not important but it must be clearly shown that it is not important before we accept it. I submit that we are always going to have problems with insoluble drugs, insoluble additives, sophisticated formulations, those drugs which show dose-dependent kinetics and those drugs which are metabolized by gut flora. An example of the latter is cyclamate which in some people is $50-60 \%$ metabolized by gut flora; because the metabolism varies, this may have a big effect on absorption.

The very minimum regulation surely must be that if a new product is to be marketed when the drug is out of patent, evidence of comparable biological profile in man must be shown. I hope I have put forward sufficient evidence to indicate that we cannot have one simple dissolution test or any other in vitro test which will apply to products formulated in a different manner though we can make it apply to products formulated in one way and kept in that way provided everything is standardized. But we cannot apply this information automatically to other products.

Surely, we ought also to expect our regulatory bodies to ask for evidence of the effects of storage on biological availability. If this is asked of the original product which it should be today, then it must be asked for anything else allowed on the market subsequently. We must protect ourselves and be consistent. It is known that with sustained release preparations, the coating changes with time so that the biological availability varies. We ought also to make moves to look for better correlations of in vitro with in vivo data.

A company spends a lot of money developing a product. Firstly, the drug is developed and patented. Then the product is developed and the company must present a lot of detailed information about 
bio-availability and toxicology before it is released. We can argue that the manufacturer must not only recover the cost of his invention but he must plough money back into the next invention. In certain countries, the formulation must not be changed and yet, in this country, we have a double standard when it comes to generic products. At the end of a patent, it is fair that a drug becomes available for competition but only if the new product meets the same requirements as the original brand. It is fair that data on bio-availability should be made available with the full details of formulation on a confidential basis to a regulatory authority; it is not fair to insist that this information be published in a monograph which would be available to those who do not subscribe to international patents. We have come now to a situation where we must define the final product and not the drug. It is the only solution to the problem, protecting the company who have spent a lot on research, as well as the patient. This is an international problem. Although we may be able to get agreement in this country, the problem will continue to exist where people do not subscribe to patents.

I have presented some of the problems and suggest that for too long we have been saying that we know the problems exist and that they are not so big; I believe that the problems are much greater, and in the interests of the patient and of the medical practitioner, the solution is to define the product. Now if that means prescribing by trade name at this stage, then I would say prescribe by trade name, provided always that the product is defined. If we allow generic products, and I am quite happy that there should be competition as long as the interests of the patient are protected, then we must ensure the comparability of each generic product with the fully tested brand name product.

And so my advice at this stage to the hospital pharmacist would be, if you are buying a generic socalled equivalent, ask for the information about that equivalence. Is the Department leading us astray when it says 'buy generically' without providing the necessary information? I think they have some answering to do on this particular issue. If we have generic equivalents then, of course, it is up to the pharmacist, who can choose with his medical colleagues which to have. But above all, products must be defined and the official standards at present do not define them and cannot define them appropriately.

\section{Discussion}

Mr J. Fingerhut suggested that a possible solution, adopted already in some countries, would be to give a trade name to the originator of the product; subsequent manufacturers would use the generic name, thereby reducing to two the possible number of names a compound could have. Professor Beckett pointed out that this would be satisfactory only if all the products under that generic name were identical.

Professor P. Turner wondered whether a clinical trial would be required when each new formulation was introduced and accurate methods of estimation were not available. In the case of clonidine and reserpine, for example, there are no accurate methods for assessment in blood and urine. Clinical trials designed to demonstrate small differences might require a very large number of patients. Professor Beckett regarded bio-availability as a chemical rather than a biological problem, which he would like to solve by chemical means, using volunteers rather than patients. Studies in volunteers would provide the absorption profile of drugs and with the advance in techniques available for measuring blood levels, it should be possible to solve most bio-availability problems in this way. The human volunteer would be the 'burette' for the chemical solution to the problem and must be standardized, for example in terms of diet.
Professor Sir Derrick Dunlop agreed that in order to carry out the standardization of drugs, it was essential at a very early stage of drug evaluation to give drugs to patients or healthy volunteers. He wondered where these human volunteers would come from. At the moment they came from laboratory staff and students who were taking medicines too frequently. In this country we shall not be allowed to use the prisoner. Professor Beckett thought that bio-availability studies on a drug could be done with very few subjects provided they were properly controlled. The question to be answered was not therapeutic but chemical. Standardizing the man increases his value in this type of experiment.

Dr T. B. Binns, commenting on Professor Vere's suggestion that there were exceptional drugs which should be prescribed by trade name, wondered how the average clinician would know when it was desirable and when it was not desirable to use trade names. Would he not be safer to prescribe by trade names on all occasions? Professor Vere agreed with Professor Beckett that some guarantee of generic products was essential. Until it was cleared up, brand names must continue to be used to identify different products. The physician must be supplied with the necessary information on bio-availability by clinical pharmacologists, pharmacists, experimental chemists 
and manufacturers. In the absence of data on bioavailability the physician must rely on clinical efficacy and lack of toxicity. He felt that the problem was transient; now that these problems had come to light, they would surely be solved. Mr Teeling-Smith hoped that the problem was transient but thought in terms of 20 years rather than 2 years. He, therefore, assumed that brand name prescribing would be the norm for the next decade. Dr J. C. Garnham could not see how the problem could be called transient, when Manson in 1899 had advised care in the treatment of malaria with sugar-coated quinine pills because they might not be absorbed from the gastrointestinal tract. Quinine was enjoying a revival of interest and of twenty-seven oral forms which are or have been used in man, it was still difficult to say which was the standard; blood levels produced even by the most commonly used varieties had not been compared.

Neither Dr J. C. Garnham nor Dr T. B. Binns were convinced that the problem of variable bioavailability was as unusual as others suggested. Dr Garnham quoted the work of Wagner (1971) suggesting that where carefully controlled clinical studies had been carried out, the predominant finding was non-equivalence of different products. Dr Binns had been involved with the World Health Organization (1973) bio-availability study in which an uncomfortable number of examples of differences in bio-availability were found.

Dr A. Herxheimer argued that bio-availability did not affect the issue of whether drugs should be prescribed by trade names or approved names. Identifying the manufacturer of a product does not eliminate variation in the bio-availability of drugs.

There was a difference of opinion between Dr F. Hartley and Professor Beckett about the value of official standards of formulation. Dr Hartley cited the Digoxin affair in support of the value of official standards though he recognized that much more work was needed to develop new methods. Professor Beckett was against the non-critical acceptance of inadequate standards for products at the present time because they might mislead the practitioner. Compliance with standards does not guarantee the bio-availability of the product; nor does a standard applied to one formulation necessarily have any meaning when a different formulation is tested. Only if the product is completely defined, including the active compound, additives and everything else about it, can an in vitro test be said to be useful in predicting bio-availability.

Professor Beckett, stressing the importance of identifying each formulation of a drug, noted that in many cases, information on bio-availability of a brand product was not publicly available. On the other hand, that product had been subjected to detailed tests including toxicology and clinical trials, which defined its properties. Comparability of a generic product could not be established unless similar data were available. A generic product may even be more completely absorbed than its branded counterpart, making it either more effective or more toxic. For these reasons, each brand product must be identifiable and its properties known and available to the practitioner. If generic prescribing led the patient to receive different formulations with different properties, it was not possible to ensure that his interest was served by having the same treatment in hospital and general practice, regardless of the source of medication. The same name should never be given to different products. Professor Beckett thought that this would apply particularly in the era of sophisticated formulation which we are entering with preparations like intrauterine hormones, though Professor Vere saw no reason why regulatory bodies could not devise generic names for them. Professor Vere wondered whether, if the nature of a drug was obscured by its inappropriate name, there was any point in considering the bio-availability of the active constituent; Professor Beckett hoped that in future there would be fewer preparations to worry about, though Professor Vere noted that the halflife of brand names tended to be long.

Dr J. C. Garnham suggested that the problems would only be resolved by a combined concerted effort by industry, the regulatory bodies and doctors working in the National Health Service.

\section{References}

Manson, P. (1899) Tropical Diseases. Cassell, London.

WAGNer, J.G. (1971) Biopharmaceutics and Relevant Pharmacokinetics. Drug Intelligence Publications, Hamilton Press, Hamilton.

World Health Organization Technical Report SERIES (1973) (in press). 